\title{
CONTEMPORANEIDADE, GLOBALIZAÇÃO E IMAGENS CONTRADITÓRIAS DA EXPANSÃO DO SISTEMA PENAL BRASILEIRO: DO INIMIGO DO DIREITO À NEUTRALIDADE DA PUNIÇÃO
}

\author{
Bruno Rotta Almeida ${ }^{1}$ \\ Taísa Gabriela Soares ${ }^{2}$
}

Resumo: $\mathrm{O}$ artigo analisa as imagens contraditórias da expansão do sistema penal brasileiro na contemporaneidade a partir das consequências da globalização. Busca compreender em que medida a neutralidade da punição contemporânea contempla a conjuntura em torno do inimigo no direito penal. Em um primeiro momento, apresenta aspectos sobre a contemporaneidade e a globalização. Após, expõe os caracteres da expansão punitiva diante da (in)segurança. Em seguida, mostra a incidência do inimigo no direito (penal). Por fim, elucida as imagens contraditórias do sistema penal brasileiro e a neutralidade da punição. $\mathrm{O}$ texto utiliza revisão bibliográfica e método dedutivo.

Palavras-chave: Globalização, Sistema Penal, Contradição, Punição, Brasil.

\section{CONTEMPORANEITY, GLOBALIZATION AND CONTRADICTORY IMAGES OF THE EXPANSION OF THE BRAZILIAN CRIMINAL SYSTEM: FROM THE ENEMY OF THE RIGHT TO NEUTRALITY OF PUNISHMENT}

\begin{abstract}
The article analyzes the contradictory images of the expansion of the Brazilian criminal system in the contemporaneity from the consequences of globalization. It seeks to understand to what extent the neutrality of contemporary punishment contemplates the conjuncture about the enemy in criminal law. At first, it presents aspects about contemporaneity and globalization. It then exposes the punitive expansion characters with respect to (in) security. It then shows the incidence of the enemy on the law (criminal). Finally, it elucidates the contradictory images of the Brazilian penal system and the neutrality of punishment. The text uses bibliographic revision and deductive method.
\end{abstract}

Keywords: Globalization, Criminal System, Contradiction, Punishment, Brazil.

\section{INTRODUÇÃO}

O Direito Penal sempre ocupou um papel de destaque nas sociedades. Desde os

\footnotetext{
${ }^{1}$ Doutor e Mestre em Ciências Criminais pela Pontifícia Universidade Católica do Rio Grande do Sul (PUCRS). Estágio de Pós-Doutorado em Criminologia e Sociologia Jurídico-Penal pela Universitat de Barce-lona (UB). Professor Adjunto da Faculdade de Direito da Universidade Federal de Pelotas (UFPel). Professor Permanente do Programa de Pós-Graduação em Direito - Mestrado em Direito da UFPel. Coordena o Libertas - Programa Punição, Controle Social e Direitos Humanos. Coordena e é advogado do Defensa - Assessoria Criminal Popular e da Clínica Jurídico-Penitenciária - Faculdade de Direito da UFPel.

2 Mestranda em Direito pelo Programa de Pós-Graduação em Direito da Universidade Federal de Pelotas, Bolsista CAPES/PIB-MD-UFPel. Graduada em Direito pela UFPel.
} 
primórdios, a noção de condutas desejadas e, consequentemente, de indesejadas esteve presente nas civilizações como condição axiológica de sua própria existência. Ademais, o Direito Penal sempre traduziu o controle do poder exercido nas sociedades, seja qual for o contexto, sempre existiu uma ligação direta entre esta ciência e o poder instituído.

Desde o modelo pós-industrial, podemos perceber mudanças expressivas na direção da ciência penal. Muito embora tenha atingido seu ápice com os modelos de governo autoritaristas, atualmente, o tema encontra novas perspectivas com o advento da globalização e de novas conjecturas em torno da punição.

Assim, o artigo, construído a partir do método dedutivo, analisa as imagens contraditórias da expansão do sistema penal brasileiro na contemporaneidade a partir das consequências da globalização. Busca compreender em que medida a neutralidade da punição contemporânea pode contemplar a conjuntura em torno do inimigo no direito penal.

Em um primeiro momento, apresenta aspectos sobre a contemporaneidade e a globalização. Após, expõe os caracteres da expansão punitiva diante da (in)segurança. Em seguida, mostra a incidência do inimigo no direito (penal). Por fim, elucida as imagens contraditórias do sistema penal brasileiro e a neutralidade da punição. O texto utiliza revisão bibliográfica e método dedutivo.

Através de observações realizadas a partir do estudo bibliográfico acerca dos elementos da expansão punitiva e do estabelecimento de uma punição contraditória e neutra, podemos traçar um quadro objetivo do cenário de ampliação da intervenção penal. É possível identificar como o uso da ferramenta do sistema penal reflete o tipo de controle exercido nas sociedades, suas consequências, funções e pretensões.

O presente artigo contribui para a reflexão sobre as perspectivas contemporâneas de atuação do sistema penal, ao indicar novas experimentações e resultados, de modo a buscar, antes de tudo, o resgate da consciência humana de sua própria noção de humanidade.

\section{CONTEMPORANEIDADE E GLOBALIZAÇÃO}

As primeiras insurgências verificadas no início do século XX deu conta de uma nova concepção de mundo, contrariando e desafiando as velhas bases anteriores. Tratava-se de "um mundo em revolução, não só contra o positivismo, mas contra todos os padrões de valores e

\footnotetext{
Revista de Criminologias e Políticas Criminais | e-ISSN: 2526-0065 | Belém | v. 5 | n. 2 | p. 01 - 20 | Jul/Dez. 2019. 
convenções burguesas, o racionalismo e convencionalismo, em geral" (GAUER, 2006, p. 187).

Segundo Franklin Le Van Baumer, a partir daquilo que seria o triunfo do devir, ${ }^{3}$ elucida que a primeira metade do século XX foi marcada por uma grande revolução no pensamento europeu, que, em um pequeno espaço de tempo, destruiu grande parte dos "ídolos" que tinham sido construídos, tanto pela idade média quanto pelos tempos modernos. Para o autor (BAUMER, 1977, p. 167), "foi uma época em que uma espécie de modernidade deu lugar, por fim, a outra". Conforme Franklin Le Van Baumer (1977, p. 167 ss.), há o triunfo do espírito do tempo sobre o espírito do espaço. Em outras palavras, tudo se encontra, agora, perpetuamente agitado, em permanente movimento, realizando mudanças e alterações; sendo assim, revela-se totalmente oposto do anterior mundo estático, inalterado e absoluto.

Deve-se destacar, portanto, a revolução ocorrida nas ciências nos primeiros anos do século passado, desencadeada pela insurreição ocorrida na Física, a partir de Max Planck e Albert Einstein, principalmente, com o nascimento da teoria quântica e da relatividade. Essas teorias desempenharam o papel de precursores do afastamento das ideias absolutas e sólidas apontadas até então sobre o tempo.

Ainda, as leis da natureza da física demonstravam-se a partir de um conhecimento ideal, o qual visa encontrar a certeza, pois, por meio das condições dadas, tudo poderia ser determinado (PRIGOGINE, 1996, p. 19). Por outro lado, vivemos, atualmente, um universo em evolução, aonde aquelas velhas leis da natureza possuem um novo entendimento: não tratam mais de certezas morais, mas sim de possibilidades. Segundo afirma Ilya Prigogine (1996, p. 159), elas "afirmam o devir, e não mais somente o ser. Descrevem um mundo de movimentos irregulares, caóticos, um mundo mais próximo do imaginado pelos atomistas antigos do que das órbitas newtonianas".

Ademais, como relata Ruth Maria Chittó Gauer, uma nova conjuntura do conhecimento afeta a visão do tempo que lhe está associada. Ou seja, uma vez se tornando incerto o tempo, torna-se, assim, distinto em relação ao tempo das ciências modernas, onde era definido conforme a pretensão de determinar leis universais/eternas da natureza. Dessa

\footnotetext{
${ }^{3}$ Para Franklin Le Van Baumer (1977, p. 167), a antiga modernidade realizou importantes mudanças na imagem do mundo, além de deixar intactos algumas concepções do ser. No entanto, a nova modernidade afastou o ser, “deixando os homens sem pontos de referência e colocando-os à deriva num mar infinito de devir".
} 
forma, "a produção de conhecimento, privado da verdade universal, somente pode ser apoiada mediante uma postura de conhecimento provisório" (GAUER, 2006, p. 175).

Por conseguinte, saímos de um mundo idealizado objetivamente para um mundo sobreposto por um pluralismo de verdades. Encontramo-nos perante um mundo de interpretações e narrativas (GAUER, 2006, p. 177); um mundo de não-equilíbrio; um mundo de não mais certezas, e sim, possibilidades (PRIGOGINE, 1996, p. 13).

Destarte, estamos diante de um universo em construção: “o futuro não é dado. Vivemos o fim das certezas" (PRIGOGINE, 1996, p. 193). Consoante Ilya Prigogine, o que advém hoje é uma descrição mediana, posicionada entre duas representações de mundo: por um lado, o mundo determinista; por outro, o mundo arbitrário submetido somente ao acaso. Para o autor (PRIGOGINE, 1996, p. 199), as leis não governam o mundo, mas este tampouco é regido pelo acaso. As leis
físicas correspondem a uma nova forma de inteligibilidade que as representações
probabilistas irredutíveis exprimem. Elas estão associadas à instabilidade e, que no
nível microscópico, quer no macroscópico, descrevem os eventos enquanto
possíveis, sem reduzi-los a consequências dedutíveis ou previsíveis de leis
deterministas.

Não obstante, de acordo com Ruth Maria Chittó Gauer (2006, p. 177), o “abandono da vontade de verdade como busca do absoluto ocasiona uma certa desordem na tradição do conhecimento cientifico. O motivo por que assim acontece é pelo fato de essa mutação implicar, também, uma mutação no nível da própria temporalidade”. O tempo torna-se impalpável, e sua intensa velocidade gera um mundo desvirtuado, desorientado, em descontrole, afetando profundamente as próprias relações interpessoais. Algumas constatações dessas quebras de paradigmas podem se relacionar com o advento/nascimento/surgimento/instauração do que se chamou de globalização.

Os cientistas (físicos) do início do século passado, ao desmantelarem as noções deterministas da certeza, desvendaram um mundo totalmente fora do nosso controle e tomado de incertezas. Trata-se de um mundo em descontrole, para usar a expressão de Anthony Giddens (2003, p. 14).

Observamos, como demonstrado inicialmente, a verificação de uma importante transição no pensamento científico; essa passagem revolucionária respingou em outras dimensões do saber, ocasionando, até mesmo, ingerências nas relações político-sociais. Para Giddens, a globalização está reestruturando, de modo profundo, a maneira como vivemos, 
influenciando na vida cotidiana na mesma medida da ocorrência de eventos em uma grandeza global. A globalização colabora para o estresse e as tensões que comprometem as relações sociais e as culturas tradicionais em muitas regiões do globo (GIDDENS, 2003, p. 15-16).

A globalização é, por conseguinte, tanto econômica quanto política, tecnológica e cultural. Ela se revela como um conjunto complexo de processos, operando de formas dessemelhantes e antagônicas. Ela estaria, segundo Anthony Giddens (2003, p. 21 ss.), destruindo culturas locais, como também ampliando ainda mais as desigualdades mundiais e piorando a situação dos empobrecidos.

\section{3 (IN)SEGURANÇA E EXPANSÃO PUNITIVA}

Não obstante, presenciamos, também, ao que Zygmunt Bauman referiu de decadência da comunidade. A comunidade é, conforme o autor, a divisão perfeita entre os "nós" e os "eles", entre os "de dentro" e os "de fora", lugar onde o isolamento entre ambos é quase completo (BAUMAN, 2003, p. 18). O que se busca na comunidade é o equivalente a um abrigo nuclear; a comunidade que pretendem é um "ambiente seguro", sem a incidência de contraventores e protegida de invasões externas. Assim, a comunidade significa o isolamento, a separação por meio de "muros protetores" e "portões vigiados" (BAUMAN, 2003, p. 103).

No entanto, essa ideia de proteção/segurança começa a se deteriorar quando as comunicações entre os "de dentro" e os "de fora", antes direcionadas ao interior, começam a embaçar a distinção entre "nós e "eles". Aqueles mesmos muros sólidos e protetores se arruínam na medida em que a comunicação entre os que estão dentro e o exterior começa a ser mais intensa do que as relações tão-somente internas. Neste ponto, Zygmunt Bauman (2003, p. 18) aponta a informática, e sua capacidade de fluxo comunicativo sem depender de seus portadores, como o golpe mortal na naturalidade do entendimento comunitário. A comunidade, por conseguinte, restará frágil e vulnerável, necessitando de defesa, vigilância, reforço e segurança.

A busca e o desejo pela segurança é a procura pelo novo erguimento das muralhas da comunidade. Porém, no mundo em que vivemos em meados do século XXI, essas muralhas estão distantes de serem rígidas; elas são/estão fundamentalmente móveis, possibilitando que 
sejam reposicionadas de acordo com mudanças sucessivas de necessidade ou desejo (BAUMAN, 2003, p. 45).

Importante fazer menção, nesta oportunidade, aos reflexos da sociedade do risco, referida por Ulrich Beck (1998, p. 28 ss.). Para o sociólogo alemão, os riscos e perigos dos dias de hoje se diferenciam da Idade Média em razão da dimensão global de suas ameaças; são riscos da modernização, desencadeados por meio do progresso e desenvolvimento do próprio período técnico-industrial. Por outro lado, a gestão política e as instituições de controle e proteção dos riscos atuam por meio de uma promessa de segurança, a qual cresce na mesma proporção que os respectivos riscos. Estes riscos penetram dentro de uma extensão globalizada, ameaçando/afetando, além das questões econômicas e tecnológicas, como também relações político-sociais. A busca por proteção/segurança torna-se uma importunação perseverante.

Importante aspecto da busca por segurança é encontrado em Globalização: as consequências humanas, também de Zygmunt Bauman: quaisquer elementos da busca por segurança, relacionados ao espetacular, torna o combate ao crime, como o próprio crime, "um excelente e excitante espetáculo, eminentemente assistível” (BAUMAN, 1999, p. 126). Dessa forma, o efeito geral que temos é a autoprodução do medo (BAUMAN, 1999, p. 127). Por outro lado, o endurecimento da política criminal, como a construção de prisões, e a elaboração e multiplicação de leis mais severas, incrementam os índices de popularidade dos governos.

O que observamos, assim, é a produção de insegurança através dos mecanismos de comunicação. Não olvidamos dos órgãos que produzem e transmitem a notícia, alocados como um símbolo social na sociedade da informação (MASUDA, 1982), além de serem compreendidos como uma das principais formas de conhecimento. Trata-se de um modelo social também caracterizado pela insegurança e pelo medo, alguns aspectos trazidos por uma exacerbação da mensagem, fazendo constituir equívocos, incertezas, ansiedade e insegurança. Não afastamos, também, o fascínio e o desejo pela imagem do crime, bem referidos na passagem de Winfried Hassemer e Francisco Muñoz Conde (1989, p. 31): "no sólo 'lo criminal', también el 'criminal' fascina. La historia de la literatura está llena de crimen y castigo, criminalidad y Derecho penal". Por fim, essa planejada rede de influências entre os meios de comunicação, o poder público e a população foi denunciada por Eugenio Raúl Zaffaroni (1991, p. 127-128): 
Os meios de comunicação social de massa - especialmente a televisão - são hoje elementos indispensáveis para o exercício de poder de todo o sistema penal. Sem os meios de comunicação de massa, a experiência direta da realidade social permitiria que a população se desse conta da falácia dos discursos justificadores; não seria, assim, possível induzir os medos no sentido desejado, nem reproduzir os fatos conflitivos interessantes de serem reproduzidos em cada conjuntura, ou seja, no momento em que são favoráveis ao poder das agências do sistema penal.

Voltando à comunidade de Zygmunt Bauman (2003, p. 102), a ideia de segurança é tocante a cada indivíduo; a defesa do lugar é vista como a condição necessária de toda segurança; esta deve ser tratada em uma estatura comunitária. Nesse sentido, e referindo-se aos guetos especificamente, indaga-se se onde o Estado fracassara poderia a comunidade, corporificada em um local habitado somente por seus membros, prover aquele sentimento de segurança que, ao mesmo tempo, é alvo de conspiração externa a fim de destruí-lo. Zygmunt Bauman (2003, p. 109) vai afirmar que o gueto é a impossibilidade de uma comunidade. Para tanto, o autor trabalha com a aproximação do gueto e a prisão, sendo entendidos como modelos de estratégia de prender os indesejáveis, como também de confinamento e de imobilização. A ideia da guetificação complementa a criminalização da pobreza, havendo uma permanente troca de população entre os guetos e as penitenciárias, um servindo como abundante fonte para a outra.

Em O mal-estar da pós-modernidade, Zygmunt Bauman (1998, p. 51) refere o elevado aumento da população carcerária e dos funcionários que trabalham em torno das instituições penitenciários, a partir da década de 1970. Lembra o autor que as manobras políticas do Estado do bem-estar foram concebidas visando reabilitar os inaptos e estimular aqueles que já se encontravam habilitados. Entretanto, atualmente, diante de um grande contingente da população que nunca reingressará na produção, não se verifica mais o interesse por parte dos políticos e gestores. Segundo se discursa: não se pode mais custear as providências do bem-estar.

Ao lado dessa transição de patamares na política relativa à criminalidade, também visualizamos o advento de um modelo de intervenção penal de segurança cidadã. Para Antonio García-Pablos de Molina (2008), algumas são as características dessa tendência de Política Criminal. Em um primeiro momento, o autor aponta o protagonismo da delinquência convencional e correlativo favorecimento da criminalidade dos poderosos, em que a política criminal volta-se novamente para a criminalidade clássica, dos crimes contra a pessoa e contra 
o patrimônio. Junto a isso, as preocupações com o problema criminal e o temor de vir a ser vítima de um delito têm se difundido na opinião pública, gerando um sentimento coletivo de insegurança e de medo do crime. Ainda, verifica-se uma exacerbação e substantividade dos interesses das vítimas, como representante dos próprios interesses e demandas.

O populismo e a politização partidária também são, para García-Pablos de Molina (2008, p. 483 ss.), uma característica da segurança cidadã, uma vez que a opinião especializada encontra-se cada vez mais desacreditada, com exceção da perícia policial. O endurecimento do rigor penal e revalorização do componente aflitivo da punição, por meio de uma vingança social, tomam uma posição de destaque. Somado a isso, atualmente se intensifica a opinião de que vale mais a pena, em resposta à criminalidade, renunciar $a$ cautelas e prevenções clássicas em benefício de uma maior efetividade e rendimento do sistema legal.

Por outro lado, um novo modelo de comunidade assume protagonismo direto, traduzido em uma colaboração com a polícia, com o objetivo de prevenir o delito e a delinquencia, pretendendo-se deter os indivíduos infratores. Por fim, a atual fórmula que se identifica na intervenção penal se orienta por um incremento do rendimento e da efetividade do controle social, inclusive penal.

A expansão do sistema penal se apresenta como produto de uma espécie de perversidade do aparato estatal, buscando do legislador penal uma aparente solução fácil aos problemas sociais, movendo ao plano simbólico aquilo que poderia ser resolvido no âmbito instrumental. Como pressuposto legitimador fundamental de determinado modelo de intervenção penal adotado, encontra-se a Constituição, Lei Maior do Estado Democrático de Direito (SOUZA, 2007, p. 32).

Não obstante, se anteriormente tínhamos o combate aos inimigos revolucionários ou reformistas radicais, forças que tentavam rebelar-se contra a ordem existente e o Estado, hoje nós temos uma sociedade de consumidores que precisa afastar do jogo aqueles jogadores incapazes e inaptos de fazerem parte do grupo desejado.

Dessa forma, segundo Zygmunt Bauman (1998, p. 56), as classes perigosas são redefinidas como classes de criminosos; e a prisão, agora, faz o papel das velhas instituições do bem-estar. No mesmo sentido, encontramos a passagem do Estado-providência ao Estadopenitência, de Loïc Wacquant (2001, p. 77 ss.), sobre a política de encarceramento de pobres 
nos Estados Unidos, nas últimas três décadas. Verificamos, também, o fim de um período chamado de penal-previdenciário e o início de uma nova cultura do crime, relativa a um neoconservadorismo altamente retributivo, referido por David Garland (2008, p. 143 ss.).

Como resultado, assiste-se a uma tendência de endurecimento da persecução penal que passa não só pelo agravamento das penas, como também pela tentativa de flexibilização de garantias individuais que representam, em última instância, formas de proteção de direitos humanos fundamentais universalmente reconhecidos, amparados e protegidos (SOUZA, 2007, p. 54). A expansão do Direito penal tem outras causas além da alegada perversidade estatal. Mesmo nos casos em que caibam reações distintas à pena ou mesmo penais de menor intensidade, é inegável que a autocompreensão da sociedade dirige demandas significativas de intervenção punitiva ao Direito do Estado.

\section{O INIMIGO E O DIREITO (PENAL)}

Terminologia criada por Günther Jakobs, em 1985, a qual pode ser vista como resultado da adição de fatores da expansão do Direito Penal. O inimigo é o individuo que, mediante seu comportamento, sua ocupação profissional ou, principalmente, mediante sua vinculação a uma organização criminosa, abandona o Direito de modo supostamente duradouro, não somente de maneira incidental. Em todo o caso, é alguém que não garante a mínima segurança cognitiva de seu comportamento pessoal e manifesta este déficit por meio de sua conduta. As características deste Direito Penal do inimigo seriam a ampla antecipação da proteção penal, a ausência de uma redução de pena correspondente a tal antecipação, o trânsito da legislação jurídico-penal para a legislação de luta, e a relativização ou supressão de garantias processuais (CANCIO MELIÁ, 2008).

De acordo com Günther Jakobs, todos os seres humanos, enquanto pessoas tem a cômoda ilusão de que estão vinculados entre si por meio do Direito (CANCIO MELIÁ, 2008, p. 25). Tal vínculo só se dá entre pessoas titulares de direitos e deveres, ao passo que a relação com um inimigo, não irá se determinar pelo Direito, mas pela coação. Assim,

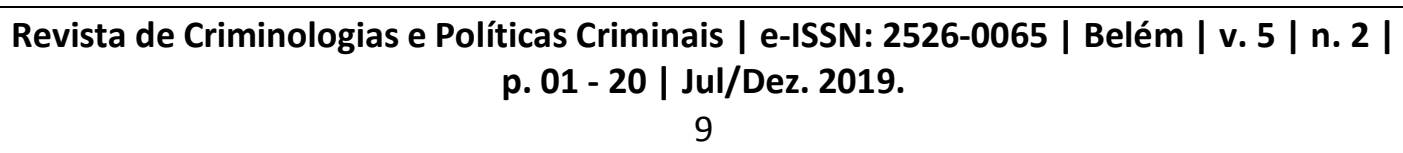


consequentemente, considerando que a coação mais intensa é a do Direito Penal, poderíamos afirmar que qualquer pena, ou, inclusive, qualquer legítima defesa se dirige contra um inimigo.

Assim visto o inimigo, parece que o modo de afrontá-lo seria o recurso a meios de asseguramento cognitivo que não teriam a natureza de pena. $O$ trânsito de cidadão para inimigo produzir-se-ia mediante a reincidência, a habitualidade, a profissionalidade delitiva e a integração em organizações delitivas estruturadas. Neste trânsito, mais além do significado de cada fato delitivo concreto, se manifestaria uma dimensão fática de periculosidade, sujeita, portanto, a medidas de segurança aplicáveis aos imputados perigosos.

O âmbito dos inimigos apresenta ainda uma dimensão adicional: de negação frontal dos princípios políticos ou socioeconômicos básicos do nosso modelo de convivência. Por sua vez, em casos desta natureza, surgem dificuldades ainda maiores de persecução e prova, além do que, tais condutas não apenas desestabilizam uma norma em concreto, mas todo o Direito. Daí por que é possível apresentar a questão do incremento das penas paralelamente à relativização das garantias substantivas e processuais. Todavia, isso somente pode se manifestar como instrumento de abordagem de fatos de emergência, sendo expressão de um Direito de guerra (SILVA SÁNCHEZ, 2001, p. 164 ss.).

Em relação à legitimidade desse Direito penal do inimigo, ele certamente deveria basear-se em considerações de absoluta necessidade, subsidiariedade e eficácia, em um marco de emergência. Mas ainda resta a questão conceitual de se, então, o Direito Penal do inimigo segue sendo Direito ou, pelo contrário, um não-Direito, uma pura reação defensiva, esta última opção nos parece mais realista.

Na prática, no contexto moderno da América Latina, sempre praticamos o chamado Direito Penal do inimigo, uma vez que este pode ser encontrado nas chamadas medidas de segurança, prisões preventivas - penas de pura contenção -, e em todo positivismo criminológico. Falar em periculosidade de uma pessoa é falar de um inimigo, temos teorizado o Direito Penal justificando medidas que são próprias do Direito Penal do inimigo.

Adentrando em um pensamento latino-americano, podemos citar Eugenio Raúl Zaffaroni, ao verificar a expressividade da violência ao longo dos tempos:

A história ensina que os conflitos que não terminam em genocídio se solucionaram pela "negociação", que pertence ao campo da política. Porém, a globalização, ao

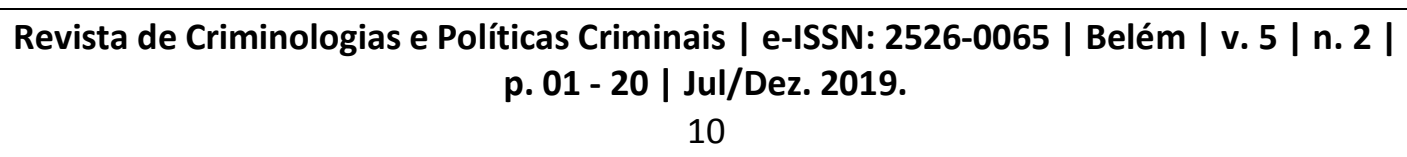


debilitar o poder de decisão dos Estados nacionais, empobreceu a política ate reduzila à sua expressão mínima. As decisões estruturais atuais assumem, na prática, a forma pré-moderna definida por Carl Schmitt, ou seja, limitam-se ao mero exercício do poder de designar o inimigo para destruí-lo ou reduzi-lo à impotência total. Qualquer pessoa que lê um jornal - aqui, voltamos para o papel dos veículos de comunicação em massa -, informa-se dos passos que o poder mundial toma rumo aos genocídios, ou seja, rumo ao aniquilamento total daqueles a quem considera seus inimigos (ZAFFARONI, 2011, p. 17).

Ainda, conclui o autor:

Como resultado desta sensação de minimização da política e da negociação, duas frentes vão sendo delineadas no mundo do pensamento, com seu natural impacto no mundo politico: a dos direitos humanos e da negociação, por um lado e, por outro, a da solução violenta que arrasa os direitos humanos e, mais cedo ou mais tarde acaba no genocídio (ZAFFARONI, 2011, p. 17).

Não obstante às marcas deixadas pelo poder punitivo de regimes autoritários, nos parece que o novo autoritarismo do século XXI, por mais que se apresente de modo diverso e, por vezes, de maneira atenuada, ainda conserva muitos aspectos bárbaros de outrora.

Importante referir que as instituições são a materialização de uma estrutura social ou de um modo de socialização em que o racismo é um de seus componentes orgânicos; é dizer: "as instituições são racistas porque a sociedade é racista" (ALMEIDA, 2018, p. 36). As urgências da realidade da nossa margem e os gritos dos cadáveres e afetados, dizendo que estão mortos, exigem visibilidade. O eixo condutor da análise não pode ser outro a não ser as mortes e as violências. Essa realidade inegável - a dos mortos que gritam que estão mortos também diz para a criminologia que aí está seu eixo condutor (ZAFFARONI, 2011, p. 14 ss.)

A abordagem do sistema penal, à luz da história social, deve ser realizada considerando a estruturação da punição no seio do poder punitivo estatal e reveladora do aparato de exclusão social e dos alvos das políticas públicas (PEDROSO, 2002, p. 30 ss.). Embora englobadas em diferenciadas técnicas de dominação, os efeitos, os saberes, as técnicas e as estratégias de domesticação escravistas que se prolongaram nos exercícios de controle da população em muitos países latino-americanos, independente do regime político e da forma de exercício de governo, fundamentaram a permanência e o possível diagnóstico de uma economia da punição própria à escravidão e à seletividade dos sujeitados à justiça penalpolítica (SOLAZZI, 2007, p. 24). 


\section{IMAGENS CONTRADITÓRIAS DO SISTEMA PENAL BRASILEIRO E A NEUTRALIDADE DA PUNIÇÃO}

O sistema penal brasileiro esboça desde há muito imagens contraditórias. Aliado a isso, os diagnósticos e as respostas, também, têm demonstrando-se incoerentes. As reivindicações político-criminais vêm se direcionando de forma ambivalente. A luta pela redução e pelo abandono convive com a da expansão e retribuição. Enquanto vem se evidenciando a debilidade dos potenciais garantidores do Direito, continua se apostando neles (ANDRADE, 2003, p. 296).

O movimento reformador da justiça criminal, ligado à forma republicana de responsabilidade criminal, coroou-se no Brasil com o Código de 1940, no qual todas as virtudes de uma justiça criminal estariam alicerçadas antes sobre pressuposto de recuperação do sentenciado do que na simples punição à ofensa criminal cometida e imputada. No entanto o Código Penal de 1940 não se desvinculou do paradigma clássico do direito penal. Ao contrário, o legislador optou por uma tentativa de conciliar pressupostos antagônicos. A aplicação do tratamento individualizado da pena não abriu mão do caráter exemplarmente punitivo da sanção criminal-judiciária. Os contrastes entre a teoria e a prática, entre os códigos e as realidades/sociabilidades carcerárias são propósitos introduzidos nas políticas públicas penitenciárias e nas correspondentes práticas institucionais (FISCHER; ADORNO, 1987, p. 74 ss.).

Essas políticas se apoiam, muitas vezes, na necessidade de criação de novas vagas (construção de presídios) e, quando menos conservadoras, na diminuição/redução/racionalização da carga punitiva (penas alternativas), preenchendo uma retórica presente desde há muito tempo. No exemplo das penas alternativas, um modelo de justiça criminal implantado pela Lei n. 9.099, de 1995 (Lei dos Juizados Especiais Criminais), o resultado foi no sentido do incremento da justiça penal no âmbito social, numa espécie de recriminalização de delitos até então mediados por braços institucionais anteriores ao Estadojudicial (AZEVEDO, 2000, p. 198), o que não passa de uma intensificação da violência institucional por meio da violência simbólica.

Também outras propostas de política criminal são lançadas nessa mesma direção. $\mathrm{O}$ exemplo atual mais notório dessa contradição se encontra na nova lei das prisões processuais 
e medidas cautelares (Lei n. 12.403, de 2011). Essa lei foi aprovada em 7 de abril de 2011 e entrou em vigor em 4 de julho do mesmo ano. Apresenta como característica principal a criação de medidas cautelares distintas da prisão. Desde essa lei, a prisão processual possui um caráter de ultima ratio e extrema ratio: deve ser utilizada apenas quando não for possível adotar outra medida cautelar menos gravosa (art. 282, §6 , CPP: “a prisão preventiva será determinada quando não for cabível a sua substituição por outra medida cautelar”). Em 2011, a taxa de pessoas presas sem condenação era de pouco mais de $30 \%$. Após cinco anos de vigência da lei, a taxa já aumentara em torno de $10 \%$. A lei - mais uma vez - não logrou o objetivo que sonhava.

Em 2010, a LEP foi reformada pela Lei n. 12.313. Essa norma condicionou as Unidades da Federação a criarem serviços de assistência jurídica, integral e gratuita pela Defensoria Pública, dentro e fora da prisão. A partir daquele ano, a Defensoria Pública se converteu em um órgão da execução penal no Brasil. Na grande maioria dos casos, a Defensoria Pública atuante na execução penal se vincula aos estados. Ocorre que, há poucos anos, alguns estados do Brasil nem sequer possuíam uma Defensoria Pública. Em outros, essa instituição está recém se estruturando como órgão de apoio aos socioeconomicamente vulneráveis.

Com isso, nada faz pensar que a prisão tenha sido um projeto de execução de pena, como também não o foi na Ilustração. A histórica e persistente contradição entre o plano jurídico-penal teórico e legislativo e o aplicado de forma concreta na sociedade demonstra o hiato em torno da resolução do problema penitenciário. Os iluministas, ao oporem-se ao absolutismo, fundamentaram a pena utilizando-se do direito natural e do estrito laicismo (racionalidade). Em ambos, o poder (violência) sobre os corpos substitui o poder (violência) sobre a alma. Mas tais pensamentos críticos tinham uma raiz fictícia e mantinham(veram) concepções autoritárias. Segundo Juan Bustos Ramírez (2012, p. 36), a isso se deram a amplitude e a aparente tolerância por essas novas ideias dos déspotas ilustrados: controle mínimo, mas autoritário. Para o autor, os iluministas que descobriram as liberdades também descobriram a disciplina.

As políticas penitenciárias não escaparam da conciliação de missões múltiplas. A nova utopia da pena neutra visa extirpar os sofrimentos prisionais, controlar a prisão, sujeitar as suas decisões a processos imparciais e contraditórios, solicitar as capacidades 
de iniciativa do detido, firmar os seus projetos - e legitimar, de vez -, a punição. O punir neutro possui três componentes complementares: pacto humanitário, consenso processual e ethos da performance. O pacto humanitário objetiva garantir aos condenados condições de vida aceitáveis e sustar a violência institucional. O consenso processual está relacionado ao ato de proceder da execução penal. Já o ethos da performance lida com a transformação do condenado (PECH, 2001, p. 139 ss.).

O punir neutro alavanca as políticas penitenciárias em direção ao sonho de uma pena soft, uma pena que resultaria de uma progressiva dessacralização da justiça penal, de um desmantelamento da violência estatal e dos muros entre os condenados e os cidadãos livres. Trata-se de uma pena capaz de agrupar uma multiplicidade de missões e preferências. Busca-se, de acordo com Thierry Pech (2001, p. 162 ss.), "punir sem penar", "punir sem degradar", "punir sem humilhar", "punir finalmente o menos possível". Tais aspirações preparam o terreno à pena neutra, e a nova utopia penitenciária procura sua coerência a partir dessas expectativas. Contudo a preocupação de melhorar as condições de detenção e de humanizar as práticas carcerárias aparenta-se, em geral, mais com a necessidade de reajustar periodicamente a pena aos limites da tolerância em vigor.

Também, nessa perspectiva, podemos encontrar naturalizações, tal qual a da violência estatal-institucional em nossa sociedade. A ambivalência no campo do castigo/cárcere não é bem um resultado, mas uma partida/entrada. Ela está no início do fenômeno, e não no final. Se desejamos coerência, como também almejaram os ilustradosreformadores do século XVIII e os neoiluminados-científicos do século XIX, não podemos abandonar a compreensão da temporalidade do excepcional. A temporalidade da exceção se naturaliza, impondo-se como tempo normal; é de alguma forma a exceção que anula a regra. A consequência é um curto-circuito de formas, prazos e processos. A urgência apoia-se no estado de necessidade (necessidade que faz lei) e transforma-se em uma exceção generalizada (OST, 2001 p. 359-360). E isso é dimensionado, no campo penitenciário, como a naturalização da violência institucional inerente à privação de liberdade e suas persistentes realidades/experiências/sociabilidades violadoras de condições humano-dignificantes. A reforma do castigo exibe, no seu nascituro, uma ambivalência primordial: humanizar para 
punir; punir para corrigir/regenerar/ressocializar; punir no limite da punição; punir em democracia.

O sintoma do caos é um desconcertante e permanente conflito que ocorre nas políticas e práticas penais-penitenciárias, muitas das quais parecem se mostrar incoerentes ou contraditórias entre si: obediência disciplinar versus autonomia empreendedora; incapacitação versus reforma correcional; punição versus reintegração; criminalização formal versus acertos informais entre vítimas/infratores. Segundo Pat O’Malley, vários regimes ou formas de penalidade(s) inconsistentes estão em vigor muito porque, virtualmente, todos podem estar disponíveis como opções. Ao lado da defesa dos direitos humanos das pessoas presas e das políticas assistenciais vinculadas às filosofias res (ZAFFARONI, 1991), encontram-se programas rígidos de disciplina e padrões punitivos voltados cada vez mais a castigo e segregação. Ocorre que, todas essas sanções aparentemente incoerentes podem ser unidas sob um só guarda-chuva comum: o da racionalidade política neoliberal (O’MALLEY, 2012, p. 102). A prisão do Iluminismo foi vampirizada pelos processos disciplinares de controle do corpo, tal como o cárcere é levado pela técnica político-processual, arriscando a devorar as nossas boas intenções. A utopia da pena neutra é um todo problemático. As duas faces fundamentais da problemática (neo)liberal estão na defesa dos direitos naturais da pessoa, por um lado, e na procura de regulações impessoais e segregadoras, por outro (PECH, 2001, p. 219220).

David Garland identifica na busca dos limites do Estado soberano os acessos punitivos e a retórica demonizadora não só em regimes políticos fortes, repressivos, mas, também, em regimes fracos, com extensão maior de democracia-liberdades. A soberania estatal sobre o crime tem sido negada e reafirmada independentemente da intensidade democrática ou repressiva da conjuntura estatal - já mencionamos a noção de neutralidade da pena, que serve quase que exclusivamente aos caracteres de um Estado social e democrático de Direito. A ambivalência política resulta num Estado confrontando suas próprias limitações. Uma estratégia se adapta ao princípio de realidade (ressocialização e redução da população prisional), enquanto a outra se esforça por negá-lo (demonização e aprisionomento). O penal é, para o autor, um complexo industrial que comunica uma rede de interesses comerciais e capitalistas que circunda o sistema penal contemporâneo e alimenta-se dele, assim como a

\section{Revista de Criminologias e Políticas Criminais | e-ISSN: 2526-0065 | Belém | v. 5 | n. 2 |}


indústria de armamentos se alimenta da guerra. Por derradeiro e ainda mais avassalador, a retórica das percepções e emoções invocadas pela estratégia punitiva tem o efeito de eliminar qualquer estratégia preventiva, caso se pretendesse (GARLAND, 2012, p. 80).

O movimento de sobrepenalização leva ao abandono dos objetivos de tratamento e de reabilitação da pessoa condenada, tudo em benefício de uma política de gestão do risco criminal com base na segurança. As incriminações, o aumento das tarifas repressivas, o alongamento da duração média das penas, a restrição ou abolição de alguns institutos penitenciários, como o livramento condicional e a suspensão condicional da pena ${ }^{4}$, e a vigilância eletrônica ${ }^{5}$, são algumas extensões repressivas do controle penal, isto é, da sobrepenalização, que visa à transformação interna, em termos de segurança, da lógica da intervenção penal (OST, 2001, p. 376 ss.).

Quando a segurança deixa de ser garantida a todos os cidadãos por um Estado soberano, ela tende a tornar-se um bem que, como qualquer outro, é distribuído por forças de mercado mais do que de acordo com as necessidades. Alguns grupos, que estão mais próximos do crime, tendem a ser os mais pobres e menos poderosos membros da sociedade, por conseguinte, carecerão dos recursos para comprar segurança. Isso tenderá a impulsionarnos em direção a uma sociedade fortificada, segregada e à morte de qualquer ideal cívico, na opinião de David Garland (2012, p. 80). Utilizando-se do contexto anglo-saxão, as novas políticas de prevenção do crime têm sido seriamente atormentadas pelas políticas sociais e econômicas das últimas décadas, o que tem acarretado no eclipse da solidariedade.

Vale lembrar, também, a transição da modernidade à modernidade recente, em Jock Young (2002, p. 22-23), como um movimento que se dá de uma sociedade inclusiva para uma sociedade excludente, em que, ao longo dos anos das décadas de 1980 e 1990, acarretou-se um processo social de exclusão, provocando, em primeiro lugar, a transformação e a separação dos mercados de trabalho e um aumento do desemprego estrutural, e, em segundo, a exclusão decorrente das tentativas de controlar o crime resultante das circunstâncias transformadas e da natureza excludente do próprio comportamento antissocial. A prisão passa

\footnotetext{
${ }^{4}$ O projeto n. 236/2012 do Senado Federal, que visa reformar o Código Penal brasileiro, promove a abolição do livramento condicional (CP, art. 83), da suspensão condicional da pena (sursis - CP, art. 77) e da reabilitação (art. 93).

${ }^{5}$ Vide Leis n. 12.258/2010 (previu a possibilidade de utilização de equipamento de vigilância indireta pelo condenado), e $\mathrm{n}^{\circ}$ 12.403/2011 (alterou dispositivos do CPP sobre medidas cautelares, incluindo a monitação eletrônica como tal).
}

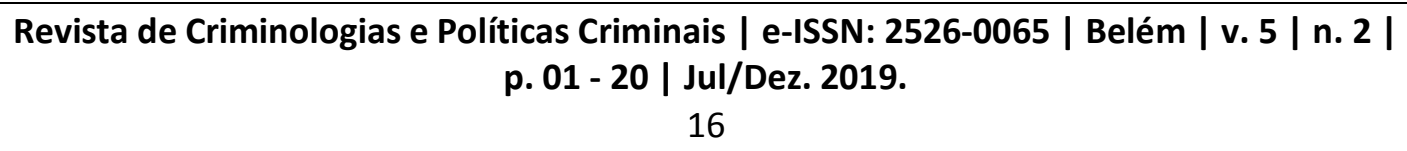


a ser concebida, de modo explícito, como um mecanismo de exclusão e, também, de controle: modalidades de tratamento ainda operam ao lado de ideais de reabilitação e exclusão. Porém a própria segregação é vista como o elemento mais importante e valioso da instituição (GARLAND, 2008, p. 380). A prisão está entre o prejuízo do funcionamento dos serviços correcionais e a tendência de neutralização dos indesejáveis (WACQUANT, 2001, p. 115).

Nesse diapasão, os modos de segregação e estigmatização penal presentes na nossa sistemática punitiva fazem com que a prisão signifique não somente uma imobilização, senão, também, uma exclusão. A prisão tem sua popularidade aumentada em razão disso, pois ela visa "arrancar o mal pela raiz". Ela proporciona uma duradoura e talvez inalterável exclusãosofrimento. A prisão tem como lema "tornar as ruas de novo seguras", removendo os perigosos (BAUMAN, 1999, p. 130). Todos esses elementos, se observamos de um mesmo plano, direcionam-se para uma constatação em comum: a identificação do crime com os desclassificados, ou a criminalização da pobreza (BAUMAN, 1999, p. 134). O encarceramento é um tipo de componente da política de contenção repressiva dos pobres, aplicada nos Estados Unidos (2001, p. 28). Para o público em geral, os delinquentes mais comuns são oriundos dos guetos/favelas urbanos, sendo considerados como áreas produtoras de crime e criminosos (BAUMAN, 1999, p. 134). Desse modo, os crimes e os criminosos são determinados e apontados pela sociedade e por meio da própria gestão política de exclusão social.

\section{CONSIDERAÇÕES FINAIS}

O artigo buscou compreender em que medida a neutralidade da punição contemporânea pode contemplar a conjuntura sobre o inimigo no direito penal. Inicialmente, esboçou algumas notas acerca da contemporaneidade e globalização. Em seguida, apresentou elementos da expansão punitiva em torno da (in)segurança. Após, apontou a incidência do inimigo no direito penal. Ao final, avaliou as imagens contraditórias do sistema penal brasileiro e o aparecimento da neutralidade da punição.

A globalização pode ser entendida como um conjugado complexo de formatos distintos e muitas vezes antagônicos. O novo levantamento das muralhas é assistido, por sua vez, pela busca e o desejo pela segurança. O endurecimento da intervenção penal e a

\section{Revista de Criminologias e Políticas Criminais | e-ISSN: 2526-0065 | Belém | v. 5 | n. 2 |}


revalorização da punição se ajustam à vingança social e tomam posição de destaque. A expansão do sistema penal se aproxima a um tipo de perversidade estatal, em que as classes perigosas são redefinidas como classes de criminosos, sendo a prisão o espaço destinado a elas.

A composição do inimigo perante o sistema penal é traduzida, em certa medida, a partir de um direito de guerra, onde operam, paralelamente, o aumento do rigor das penas e a relativização das garantias básicas do direito. No contexto brasileiro, tal modelo punitivista e, ao mesmo tempo, negacionista acompanha uma gramática histórica do castigo, eis que as instituições estão imbricadas a uma estrutura social onde o racismo é um de seus alicerces.

As missões múltiplas operadas pelo sistema penal alcançam também as políticas penitenciárias. A chamada pena neutra busca desenraizar os sofrimentos prisionais, legitimando a própria punição aos limites da tolerância em vigor. Vê-se um interesse no efeito simbólico do sistema punitivo em detrimento do efeito concreto. As exigências do Estado de Direito dão ânimo para uma nova utopia: a da neutralidade da punição. Tratase de múltiplos interesses que justificam, de certa forma, a ação violenta, mesmo diante da consolidação dos direitos fundamentais das pessoas humanas. Não é possível verificar uma orientação preocupada, eticamente, com as consequências da intervenção penal. Nota-se, por outro lado, uma direção relacionada à estética da aparente boa forma da intervenção. Tal neutralidade, além de não se afastar da conjectura do inimigo do direito, faz emergir, concretamente, uma ação desumanizadora do sistema punitivo.

\section{REFERÊNCIAS}

ALMEIDA, Silvio Luiz de. O que é racismo estrutural? Belo Horizonte: Letramento, 2018. ANDRADE, Vera Regina Pereira de. A ilusão de segurança jurídica: do controle da violência à violência do controle penal. 2. ed. Porto Alegre: Livraria do Advogado, 2003. AZEVEDO, Rodrigo Ghiringhelli de. Informalização da justiça e controle social: estudo sociológico da implantação dos juizados especiais criminais em Porto Alegre. São Paulo: IBCCRIM, 2000.

BAUMAN, Zygmunt. Comunidade: a busca por segurança no mundo atual. Rio de Janeiro: Jorge Zahar, 2003.

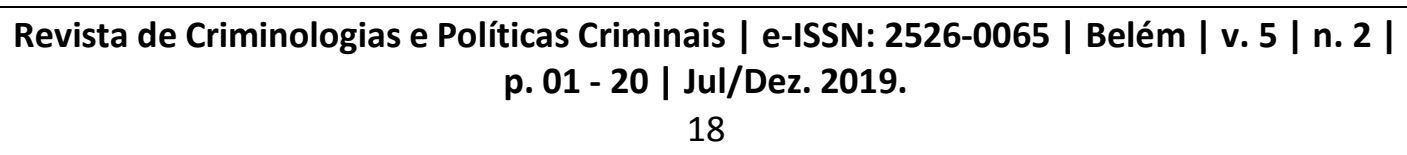


BAUMAN, Zygmunt. Globalização: as consequências humanas. Rio de Janeiro: Jorge Zahar, 1999.

BAUMAN, Zygmunt. O mal-estar da pós-modernidade. Rio de Janeiro: Jorge Zahar, 1998. BAUMER, Franklin Le Van. O Pensamento Europeu Moderno. Vol. II. Lisboa: Edições 70, 1977.

BECK, Ulrich. La sociedad del riesgo: hacia una nueva modernidad. Barcelona: Paidós, 1998.

CANCIO MELIÁ, Manuel; JAKOBS, Günther. Direito Penal do inimigo: noções e críticas.

Org. e trad.: André Luís Callegari, Nereu José Giacomolli. Porto Alegre: Livraria do Advogado, 2008.

FISCHER; Rosa Maria; ADORNO, Sergio, Políticas penitenciárias, um fracasso? Lua Nova, vol.3 no.4 São Paulo, Junho 1987.

GARLAND, David. A cultura do controle: crime e ordem social na sociedade contemporânea. Rio de Janeiro: Revan, 2008.

GARLAND, David. Os limites do estado soberano: estratégias de controle do crime na sociedade contemporânea. In: CANEDO, Carlos; FONSECA, David S. (org.) Ambivalência, contradição e volatilidade no sistema penal: leituras contemporâneas da sociologia da punição. Belo Horizonte: Editora da UFMG, 2012.

GAUER, Ruth M. Chittó. O reino da estupidez e o reino da razão. Rio de Janeiro: Lumen Juris, 2006.

GIDDENS, Anthony. Mundo em descontrole: o que a globalização está fazendo de nós. 3. ed. Rio de Janeiro: Record, 2003.

HASSEMER, Winfried; MUÑOZ CONDE, Francisco. Introducción a la criminología y al derecho penal. Valencia: Tirant lo Blanch, 1989.

MASUDA, Yonej. A sociedade da informação como sociedade pós-industrial. Rio de Janeiro: Rio, 1982.

MOLINA, Antonio García-Pablos de; GOMES, Luiz Flávio. Criminologia. 6. ed. São Paulo: Revista dos Tribunais, 2008.

O’MALLEY, Pat. Punição contraditória e volátil. In: CANEDO, Carlos; FONSECA, David S. (org.) Ambivalência, contradição e volatilidade no sistema penal: leituras contemporâneas da sociologia da punição. Belo Horizonte: Editora da UFMG, 2012. 
OST, François. O tempo do direito. Lisboa: Instituto Piaget, 2001.

PECH, Thierry. Neutralizar a pena. In: GARAPON, Antoine; GROS, Frédéric; PECH,

Thierry. Punir em democracia: e a justiça será. Lisboa: Instituto Piaget, 2001.

PEDROSO, Célia Regina. Os signos da opressão: história e violência nas prisões brasileiras.

São Paulo: Arquivo do Estado, 2002.

PRIGOGINE, Ilya. O fim das certezas: tempo, caos e as leis da natureza. São Paulo:

Universidade Estadual Paulista, 1996.

RAMÍREZ, Juan Bustos. Control social y sistema penal. Bogotá: Temis, 2012.

SILVA SÁNCHEZ, Jesús-Maria. La expansión del derecho penal: aspectos de la política criminal en las sociedades postindustriales. Madrid: Civitas, 2001.

SOLAZZI, José Luís. A ordem do castigo no Brasil. São Paulo: Imaginário; Editora da Universidade Federal do Amazonas, 2007.

SOUZA, Luciano Anderson de. Expansão do direito penal e globalização. São Paulo: Quartier Lantin, 2007.

WACQUANT, Loïc. As prisões da miséria. Rio de Janeiro: Jorge Zahar, 2001.

YOUNG, Jock. A sociedade excludente: exclusão social, criminalidade e diferença na modernidade recente. Rio de Janeiro: Revan, 2002.

ZAFFARONI, Eugenio Raúl. A filosofia do sistema penitenciário. Cuadernos de la Cárcel. Buenos Aires, 1991.

ZAFFARONI, Eugenio Raúl. Em busca das penas perdidas: a perda da legitimidade do sistema penal. Rio de Janeiro: Revan, 1991.

ZAFFARONI, Eugenio Raúl. La palabra de los muertos: conferencias de criminología cautelar. Buenos Aires: Ediar, 2011.

ZAFFARONI, Eugenio Raúl. O inimigo no direito penal. Trad. Sérgio Lamarão. Rio de Janeiro: Revan, 2011. 